\title{
ОСОБЕННОСТИ ПРАВОВОГО РЕГУЛИРОВАНИЯ НАСЛЕДСТВЕННЫХ ФОНДОВ В РФ. ДОВЕРИТЕЛЬНОЕ УПРАВЛЕНИЕ КАК ИХ АНАЛОГ
}

\section{FEATURES OF LEGAL REGULATION \\ OF HEREDITARY FUNDS IN THE RUSSIAN \\ FEDERATION. TRUST MANAGEMENT AS THEIR FNALOG}

\section{Ivanova}

Summary. In this article the author considers the novel in the legislation of the Russian Federation "hereditary Fund". The relevance of this study is due to the fact that the hereditary Fund is a typical institution for Russian legislation and reality, despite the fact that in the norms of foreign legislation such a Fund has long been common. According to the author, the inheritance Fund does not have sufficient legal regulation, which leads to a significant number of both theoretical and practical problems associated with not only the existing rules on funds, but also a new procedure for the establishment of an inheritance Fund with the participation of a notary, which creates additional rights and obligations for the notary. Systematic analysis of the legislation of the Russian Federation in the course of the study revealed some problems that require attention and, of course, resolution at the legislative level. The author offers possible solutions to the problems. In this article the author considers the novel in the legislation of the Russian Federation "hereditary Fund". The relevance of this study is due to the fact that the hereditary Fund is a typical institution for Russian legislation and reality, despite the fact that in the norms of foreign legislation such a Fund has long been common. According to the author, the inheritance Fund does not have sufficient legal regulation, which leads to a significant number of both theoretical and practical problems associated with not only the existing rules on funds, but also a new procedure for the establishment of an inheritance Fund with the participation of a notary, which creates additional rights and obligations for the notary. Systematic analysis of the legislation of the Russian Federation in the course of the study revealed some problems that require attention and, of course, resolution at the legislative level. The author offers possible solutions to the problems.

Keywords: Apartments, real estate, inheritance Fund, Fund, notary, notary actions, inheritance law, trust management, trust.

\author{
Иванова Мария Сергеевна \\ Соискатель, ФГБУН Институт государства и права \\ Российской академии наук \\ Mariaivanova1991@gmail.com
}

Аннотация. В настоящей статье автором рассматривается новелла в законодательстве РФ — «наследственный фонд». Актуальность такого исследования обусловлена тем, что наследственный фонд является атипичным институтом для российского законодательства и действительности, несмотря на то, что в нормах зарубежного законодательства такой фонд давно распространен. По мнению автора, наследственный фонд не обладает достаточным правовым регулированием, что приводит к возникновению значительного количества как теоретических, так и практических проблем, связанных с не только уже существующими нормами о фондах, но и новой процедуре учреждения наследственного фонда с участием нотариуса, что создает дополнительные права и обязанности для нотариуса. Системный анализ законодательства РФ в процессе исследования позволил выявить некоторые проблемы, требующие внимания и, безусловно, разрешения на законодательном уровне. Автором предложены возможные варианты решения проблем.

Ключевые слова: Апартаменты, недвижимое имущество, наследственный фонд, фонд, нотариус, нотариальные действия, наследственное право, доверительное управление, траст.
B настоящее время в законодательстве Российской Федерации происходят глобальные изменения, в том числе в наследственном праве. До (недавнего времени) внесения глобальных изменений в нормы наследственного права существовало 2 способа распоряжения дальнейшей судьбой наследственной массы после смерти наследодателя: наследование по закону и по завещанию. Большинство изменений в наследова- нии связано с практической целесообразностью расширения способов распоряжения наследственной массой. В нормах действующего законодательства РФ наследственный фонд закреплен с 1.09.2018 года, а именно в п. 1 ст. 4 Федерального закона № 259-Ф3 от 29 июля 2017 года «О внесении изменений в части первую, вторую и третью Гражданского кодекса Российской Федерации» были внесены существенные изменения в нормы 
Гражданского кодекса РФ, касающиеся норм о наследственных фондах, которые могут быть созданы с 1 сентября 2018 года. Главной целью создания таких фондов является управление имуществом, полученным в порядке наследования. Данный шаг представляет собой кардинальные изменения, вносимые не только в нормы ГК РФ, но и наследственного права. Несмотря на то, что нормы о наследственном фонде были внесены в законодательство в 2017 году, а вступили в силу в 2018 году, можно прийти к выводу о том, что законодатель дал время для анализа вышеназванных норм.

Необходимо отметить, что институт наследственного права является изобретением не российского права, а частично заимствован из норм зарубежного права. Так, «первооткрывателем» наследственного фонда является Германия, в частности § 83 ГГУ, «Фонд, создаваемый по распоряжению на случай смерти». Вместе с тем, наследственные фонды распространены за рубежом, но именуются трастами. Так, в романо-германской правовой семье используется конструкция штифтунг Stiftung, в англо-саксонской правовой семье - Траст Trust. В ОАЭ функционируют как фонды, так и трасты, а также аналог доверительного управления - фидуциарные услуги. По сути, и фонд, и траст представляют собой передачу конкретного имущества в управление, в результате чего образуется обособленное «целевое имущество». В США и Великобритании также существует возможность учреждать такие фонды, в том числе для благотворительных целей. В нормах законодательстве ОАЭ предусмотрена норма ст. 110 ГК ОАЭ, в которой содержится расшифровка понятия права собственности, входящие права в него называются исходными: «Исходными правами собственности, входящими в состав права собственности являются распоряжение, пользование, узуфрукт, права резидентов или нерезидентов, право сервитута, право Вакуф, а также иные права, признанные законом таковыми». Переводя на русский язык термин «Wagfs» с арабского языка, это означает: (приостановка, удержание) - в мусульманском праве имущество, которое передано государством либо отдельными гражданами на благотворительные цели. При этом, в состав Вакуф может входить как недвижимое имущество, так движимое (в том числе неотчуждаемое), но приносящее доход, а также нерасходуемое (так, например, денежные средства не могут находиться в его составе).

Вышеназванные нововведения в наследственном праве были изучены в ходе проведения международной научно-практической конференции «Российский нотариат: 25 лет на службе государству и обществу», которая была организована Федеральной нотариальной палатой и юридическим факультетом МГУ имени М. В. Ломоносова. Так, Профессор Н. Козлова указала на ряд пробелов в правовом регулировании наследственных фондов в РФ, «Основная проблема, которую я здесь вижу - это само создание наследственного фонда». Необходимо отметить, что наследственный фонд возможно создать по инициативе гражданина, указав в завещании об учреждении такого фонда и утвердить его устав. Однако, решение о создании такого фонда принимается после смерти гражданина: «Нотариус, ведущий наследственное дело, обязан направить в уполномоченный государственный орган заявление о государственной регистрации наследственного фонда не позднее трех рабочих дней со дня открытия наследственного дела после смерти гражданина, который предусмотрел в своем завещании создание наследственного фонда. Наследственный фонд не подлежит регистрации по истечении одного года со дня открытия наследства».[1] Следовательно, в том случае, если государственный регистрирующий орган при проверке обнаружит ошибки в уставе, то впоследствии откажет в самой регистрации либо внести изменения. «Устав наследственного фонда и условия управления наследственным фондом не моzуm быть изменены после создания наследственного фонда, за исключением изменения на основании решения суда по требованию любого органа фонда в случаях, если управление наследственным фондом на прежних условиях стало невозможно по обстоятельствам, возникновение которых при создании фонда нельзя было предполагать, а также в случае, если будет установлено, что выгодоприобретатель является недостойным наследником (статья 1117), если только это обстоятельство не было известно в момент создания наследственного фонда».[2]. Нормы ст. 1117 ГК РФ указывают перечень лиц - недостойных наследников, в части применимой к возможности таких лиц внести изменения в устав наследственного фонда или условий управления им на основании решения суда по требованию любого органа фонда в случае, если будет установлено, что выгодоприобретатель является недостойным наследником, если только это обстоятельство не было известно в момент создания наследственного фонда.

Следующей проблемой является расплывчатая формулировка цели создания наследственного фонда (в соответствии с нормами действующего законодательства РФ, а именно п. 1 ст. 7 ФЗ «О некоммерческих организациях» № 7-ФЗ от 12.01.1996 года, целями создания фонда могут быть «...социальные, благотворительные, культурные, образовательные или иные общественно полезные цели». Л.В. Щенникова считает, что «в наследственном фонде не осталось, по сути, ничего от основополагающих характеристик такой организационно-правовой форы некоммерческой организации, как фонд, поскольку его некоммерческий характер неочевиден, условия деятельности закрыты, он ни перед кем не отчитывается, в связи с чем в системе юридических лиц российского гражданского права наследственный фонд должен 
занимать совершенно обособленное место, не являясь однозначно некоммерческой организацией».[3] Следует согласиться с данным мнением, но отметить, что по существу законодатель используя термин «наследственный фонд» подменяет сущность внутренних взаимоотношений в рамках иной организационно-правовой формы юридического лица.

При этом, несмотря на жесткую критику норм о наследственном фонде, отдельные ученые-цивилисты выразили поддержку и необходимость внесения таких изменений. Так, Е.Ю. Петров и И.Г. Ренц в своем исследовании указали, что очевидным достоинством наследственного фонда является «предотвращение дробления имущества, характерное для наследования, высокий иммунитет имущества от обращения взыскания по долгам учредителя и бенефициаров и определенную степень конфиденциальности прав бенефициаров». [4]

Правовой режим наследственного фонда определяется на основании общих положений о фондах и иными правилами, указанными в ст.ст.123.20-123.20-2 ГК РФ, в соответствии с которыми: представляется, что наследственный фонд представляет собой отдельный, самостоятельный вид фонда, чей основной целью является в соответствии с нормами ст. 123.20-1 ГК РФ: «исполнение завещания гражданина и на основе его имущества фонд, осуществляющий деятельность по управлению полученным в порядке наследования имуществом этого гражданина бессрочно или в течение определенного срока в соответствии с условиями управления наследственным фондом».

Для создания наследственного фонда необходимо следующее:

1. Нотариально удостоверенное завещание, в котором предусмотрено решение о создании наследственного фонда. Само завещание изготавливается в 3-х экземплярах: один экземпляр хранится у нотариуса. Такое завещание может быть открытым. В случае, если нотариус принял закрытое завещание, а после смерти наследодателя обнаруживается, что условие о создании наследственного фонда отсутствует, то оно будет являться ничтожным.

Далее процедура учреждения фонда такова: заявление нотариуса (ведущего наследственное дело гражданина) не позднее 3-х рабочих дней со дня открытия наследственного дела направляется в уполномоченный государственный орган о гос. регистрации такого фонда. Если нотариус не выполняет надлежащим образом обязанности по созданию наследственного фонда, то душеприказчик либо выгодоприобретатель вправе направить в суд требование об учреждении такого фонда, и он бу- дет учрежден на основании решения суда, вступившего в законную силу. При этом, условия существования фонда определяются в соответствии с решением наследодателя и не могут быть изменены после его смерти. Несмотря на это, нормы ГК РФ содержат исключение из этого правила: устав, а также условия управления фондом могут быть изменены на основании решения суда либо в случаях, если управление фондом на «старых» условиях представляется невозможным; немаловажным исключением является установление факта, когда выгодоприобретатель будет признан недостойным наследником». Нотариус не вправе выдать свидетельство о праве на наследство, пока не будет определен круг наследников, так как такое свидетельство является подтверждением факта, что конкретное лицо - наследник. Для того, что вышеназванная норма корректно действовала, необходимо внести унифицирующие изменения нормы в ГК РФ и «Основы законодательства Российской Федерации о нотариате».[5]

Также, представляется важным пробел в законодательстве в отношении устава фонда: из вышеназванных норм, регулирующих наследственный фонд, можно сделать вывод о том, что устав должен быть внесен в текст завещания, однако, нормы абз. 1 п. 1 ст. 123.20-1 определяют список документов, которые нотариус обязан направить в регистрирующий орган для создания наследственного фонда. При этом устав наследственного фонда признан приложением к заявлению и не содержится информации о завещании.

Законодатель предусмотрел несколько случаев ликвидации фонда (абз. 1 п. 7 ст. 123.20-1 ГК РФ: «по решению суда по основаниям, предусмотренным подпунктами 1-4 пункта 3 статьи 61 настоящего Кодекса, а также в связи с наступлением срока, до истечения которого создавался фонд, наступлением указанных в условиях управления наследственным фондом обстоятельств или невозможностью формирования органов фонда (пункт 4 статьи 123.20-2)...». На основании вышеизложенного можно сделать вывод о том, что существование фонда зависит от волеизъявления самого учредителя фонда, так и от иных вышеназванных обстоятельств.

Несмотря на недостаточно разработанное правовое регулирование норм о наследственном фонде, он (фонд) имеет очевидные преимущества и недостатки. Преимуществами введения в действие норм о наследственном фонде являются следующие: 1) Непрерывное управление бизнес активами. Так, П.В. Крашенинников отмечал, что «передача имущества наследственному фонду сразу после смерти наследодателя это благо, так как позволит избежать потери прибыли. Однако этот, как его называют «новый инструмент», данный законодателем российскому бизнесу, с очевидностью будет подрывать основы 
наследственного права, так как составляет серьезное изъятие из правил универсального наследственного правопреемства».[6] 2) Наследственный фонд является дополнительным механизмом защиты наследственной массы до передачи наследникам. Так, П.В. Крашенинников считает, что «введение норм о наследственных фондах позволит, во-первых, обеспечить защиту интересов кредиторов, а, главное, несовершеннолетних детей наследодателя, и других наследников, имеющих право на обязательную долю в наследстве».

К числу неоднозначных положений, касающихся наследственного фонда, можно отнести: 1) недостаточно разработанное правовое регулирование (например, вопрос о том, что необходимо делать при обнаружении некорректных данных или при невозможности формирования органов фонда при его создании). 2) дополнительные обязанности для нотариуса, сложный механизм (ранее не имевший аналогов) образования таких фондов. 3) Размер уставного капитала в наследственном фонде не установлен законодательством, в то время как в большинстве создаваемых фондах за рубежом установлен: так, например, В ФРГ от 50 тысяч евро.

Наследственный фонд является инструментом, позволяющим организовать наследственную массу, однако, ни законопроект, ни изменения от 1 июня 2018 года и 1 июня 2019 года, не рассматривают вопрос о правовой природе и месте в системе наследственного права наследственного договора и наследственного фонда, так как они (изменения) «вплелись» в уже существующие нормы.

Необходимо отметить, что управление наследственным фондом отчасти напоминает доверительное управление имуществом в РФ (ст.ст.1012-1026 ГК РФ).

Наиболее интересна практика трастов, функционирующих в ОАЭ. Так, в отличие от РФ в Эмирате Дубай, принят отдельный Закон «Об инвестициях в трасты» 2006 года,[7] который является правовой базой для правового регулирования трастов для физических лиц и юридических лиц. Также, в вышеназванном законе специально оговорено положение о том, что потенциальные наследники могут предъявить трасту иски и имущество траста не может быть арестовано. Представляется, что данное положение имеет практический и научный интерес для российского законодательства о наследственных фондах в РФ. А также траст, учрежденный в Эмирате Дубай, позволяет избежать права на обязательную долю в наследственной массе, что предоставляет учредителю свободный выбор распоряжения своими активами. Необходимо отметить, что в отличие от законодательства РФ, законодательство ОАЭ о трасте имеет аналоги, альтернативным вариантом траста явля- ется фонд. Фонд признается юридическим лицом, для создания которого необходим факт наличия учредителя, однако он (фонд) не имеет конкретного собственника, но вправе владеть другими юридическими лицами и активами, издавать обязательные для исполнения инструкции (как в трасте). Указание на инструкции и требования к ним вносятся в регистрационный документ фонда и обязательно в его устав. Цели создания фондов разнообразны - коммерческие, благотворительные и даже частные цели (в отличие от законодательства РФ фонды в РФ признаются некоммерческими организациями), такие фонды могут быть созданы на конкретный срок. Законодательство Эмирата Дубай выделяет следующие виды фондов: 1) Публичный (создаваемый семьями, группами лиц, объединёнными для удовлетворения общей цели и т.д.; 2) Частный фонд - физическими лицами; 3) Государственный фонд; 4) Смешанный фонд учреждаемый совместно любыми вышеуказанными категориями.

Несмотря на очевидные сходства, фонд и траст имеют существенные различия:

1. При создании фонда появляется самостоятельный субъект права, а при трасте - общественные отношения, возникающие на основании договора между лицом, передавшим имущество в такой траст, и его управляющим. Таким образом, собственность на имущество, переданное в траст, переходит к управляющему траста, который осуществляет его управление.

2. Учредитель траста вправе отменить траст и вернуть право собственности на имущество, переданное в него (в отличие от учредителя фонда).

3. Фонд распоряжается переданным имуществом как юридическое лицо, а управляющим траст часто является физическое лицо.

4. Фонд вправе распоряжаться переданным ему имуществом согласно цели в уставе.

Автору представляется, что нормы о наследственном фонде имеют схожие черты с нормами о доверительном управлении. По договору доверительного управления имуществом одна сторона - учредитель управления - передает другой стороне - доверительному управляющему на определённый срок имущество в доверительное управление, а другая сторона обязуется осуществлять управление этим имуществом в интересах учредителя управления или указанного им лица - выгодоприобретателя. Согласно п. 6 ст. 1 Федерального закона от 13.07.2015 № 218-Ф3 «О государственной регистрации недвижимости» доверительное управление недвижимым имуществом, в том числе земельным участком, входит в список ограничений прав и обременений недвижимого имущества и подлежит государственной регистрации. 
Объектами доверительного управления может быть различное имущество. При этом, несмотря на то, что в составе наследственного фонда может быть любое имущество в качестве наследственной массы, нормы законодательства не учитывают особенности конкретных видов имущества. Особый интерес для доверительного управления представляют земельные участки и ценные бумаги, поскольку данные виды имущества представляют значительный интерес и определяют существующую специфику в исследуемом наследственном фонде. Так, например, в доверительное управление имуществом (по договору) может быть передан земельный участок, такой договор должен быть заключён в письменной форме и подлежит гос. регистрации как переход права собственности на это имущество. Однако, в нормах законодательства предусмотрена оговорка, что не все земельные участки могут быть объектом договора доверительного управления: земельные участки, не прошедшие гос. регистрацию и гос. кадастровый учет, а также изъятые из оборота (земельные участки, занятые государственными природными заповедниками и национальными парками, зданиями, строениями и сооружениями, в которых размещены Вооруженные силы РФ, другие войска, воинские формирования, военные суды, объектами организаций ФСБ, федеральных органов государственной охраны, объектами использования атомной энергии, пунктами хранения ядерных материалов и радиоактивных веществ, объектами, в соответствии с видами, деятельности которых созданы закрытые административно- территориальные образования, инженерно-техническими сооружениями, линиями связи и коммуникациями, возведенными в интересах защиты и охраны Государственной границы РФ и многие другие). Для передачи земельного участка в доверительное управление как самостоятельного объекта управления, а также как и в составе имущественного комплекса необходима следующая фраза в договоре: «В состав управляемого имущества на момент передачи управляющему входит земельный участок с кадастровым номером, площадью, имеющий следующий адрес (указание адреса) и ориентиры. Границы участка установлены на местности и закреплены межевыми знаками. План границ земельного участка и план земельного участка являются составной и неотъемлемой часть договора».

Следующим видом имущества, которое отличается своеобразием в рамках договора доверительного управления являются ценные бумаги. Так, в частности В.А. Дозорцев справедливо заметил, что «для ценной бумаги существенное значение имеет не ее вещественный характер. Важно, что она выражает определённые права и закрепляет их в объективной форме, притом осуществление их без подтверждения в этой форме не допускается. Поэтому специальные правила о передаче в доверительное управление ценных бумаг применяются к правам, удостоверенным бездокументарными ценными бумагами».[8] Некоторые правила о доверительном управлении ценными бумагами содержатся в нормах статьи 1025 ГК РФ. При передаче в доверительное управление ценных бумаг может быть предусмотрено объединение ценных бумаг, передаваемых в управление разными лицами, и что правомочия доверительного управляющего по распоряжению ценными бумагами должны быть определены в договоре доверительного управления - внести этот пункт в законодательство как существенное условие.

Крайне мало норм, которые регулировали отношения с доверительным управлением ценными бумагами. Несколько правил установлены Ф3 «О рынке ценных бумаг».[9] В ст. 5 вышеназванного закона расширено понятие объектов доверительного управления ценными бумагами. К их числу отнесены ценные бумаги, денежные средства, предназначенные для инвестирования в ценные бумаги, а также денежные средства и ценные бумаги, приобретаемые в процессе управления ценными бумагами. Специального закона для регулирования данных правоотношений нет. Согласно пункту 2 ст. 1013 ГК РФ предусматривает, что деньги не могут быть самостоятельным объектом доверительного управления. Они могут находиться в доверительном управлении только лишь в том случае, когда находятся в составе имущественного комплекса, для этого доверительный управляющий открывает банковский счет специально для этих денег - п. 1 ст. 1018 ГК РФ. По общему правилу, имущество, приобретенное за счет этих средств, переходит в состав имущества, переданного по договору доверительного управления. При заключении договора о доверительном управлении учредитель передаёт доверительному управляющему определенную денежную сумму на условиях, что последний совершал определённые действия по увеличению денежной массы.

В.А.Дозорцев утверждает, что существуют некие юридические и технические факторы, которые исключают возможность доверительного управления деньгами как самостоятельными, отдельными объектами. В доверительное управление, по его мнению, могут передаваться только индивидуально-определённые объекты. Право собственности на них сохраняется за учредителем, по прекращении доверительного управления именно они и возвращаются учредителю.

Остается не решенным вопрос, может ли входить в наследственный фонд имущество, находящееся в залоге, в отличие от доверительного управления: так как залогодатель остается собственником и сохраняет возможность распоряжения им. Как справедливо заметил Е.А. Суханов, привлечение к управлению таким имуществом профессионального управляющего может существенно повысить эффективность его использования 
и помочь залогодателю выполнить свои обязательства перед залоговым кредитором.[10]. Учредитель обязан уведомить доверительного управляющего об обременении имущества залогом, так как вышеназванное имущество может стать объектом взыскания со стороны залогодержателя и может быть изъято из доверительного управления. Если доверительный управляющий не знал об обременении, то он вправе в судебном порядке расторгнуть договор доверительного управления и взыскать с учредителя годовое вознаграждение согласно нормам статьи 1019 ГК РФ.
Таким образом, системный анализ норм законодательства РФ посвященных наследственному фонду, позволяет нам прийти к следующему выводу: наследственный фонд - практически определенный инструмент управления бизнес-активами, что позволяет максимально защитить интересы не только наследников, но и обеспечить сохранность бизнес-активов.

При этом, конструкцию наследственного фонда в РФ необходимо адаптировать к реалиям действующего законодательства РФ с учетом опыта зарубежных стран.

\section{ЛИТЕРАТУРА}

1. Статья 123.20-1. ГК РФ. Создание наследственного фонда, условия управления им и его ликвидация, п. 3 ст. 1 Ф3 от 29.07. 2017 г. № $259-$ Ф3 «0 внесении изменений в части первую, вторую и третью Гражданского кодекса Российской Федерации»// Собрание законодательства Российской Федерации от 31 июля 2017 г. № 31 (часть I) ст. 4808

2. П. 5 ст. $123.20-1$ Ф3 № $259-Ф 3$

3. Щенникова Л. В. Наследственный фонд как новелла Российского гражданского права // Нотариальная палата Kраснодарского края.— URL: http://notariat. redhampr.ru/notariat/publikacii/stati/2899/.

4. Е.Ю. Петров Развитие российского наследственного права / Е. Ю. Петров, И. Г. Ренц // Закон.— 2017.— № 6. — C. 44-50.

5. Семенкова В. М. Некоторые вопросы создания наследственных фондов в Российской Федерации // Молодой ученый. — 2018. — № 5.—C. 137-139.— URL https://moluch.ru/archive/191/48214/

6. Крашенинников П. В. Наследство до востребования // Российская газета. 2017. 1 августа.

7. Закон № 7 Дубая «06 инвестициях в трасты» Закон № 7 от 2006 года

8. Дозорцев В. А. Доверительное управление // Вестник ВАС РФ. 1996. ⒓ С. 120

9. Федеральный закон от 22.04.1996 N39-Ф3 (ред. от 30.12.2015) «0 рынке ценных бумаг»//»Российская газета», № 79, 25.04.1996.

10. Суханов Е. А. Договор доверительного управления имуществом//Вестник ВАС РФ,2001 